\title{
İntrauterin Gelişme Geriliği Olan Gebelerin Koroid Kalınlığının Optik Koherens Tomografi ile Değerlendirilmesi
} \author{
Growth Retardation by Optical Coherence Tomography \\ ${ }^{1} 1$ Kadın Hastalıkları ve Doğum Kliniği, Selçuk Üniversitesi Tip Fakültesi Hastanesi, İstanbul, Türkiye. \\ Yazı̧ma Adresi / Correspondence: \\ Burak Giray \\ Emek Mah., Namık Kemal Cd. No:54, 34785 Sancaktepe, İstanbul Türkiye \\ T: $+905055541590 \quad$ E-mail: burakgiray@gmail.com \\ Geliş Tarihi / Received : 21.01.2021 Kabul Tarihi / Accepted : 06.04.2021 \\ Orcid: \\ Bayram Can https://orcid.org/0000-0002-3610-9089 \\ Yunus Emre Purut https://orcid.org/0000-0001-5779-3847 \\ Burak Giray https://orcid.org/0000-0002-3832-6634 \\ Gülfidan Bitirgen https://orcid.org/0000-0002-0509-5649 \\ Ali Acar https://orcid.org/0000-0002-9074-258X \\ ( Sakarya Tip Dergisi / Sakarya Med J 2021, 11(2):395-399 ) DOI: 10.31832/smj.861550
}

Evaluation of Choroidal Thickness in Pregnant Women with Intrauterine

Bayram Can ${ }^{1}$, Yunus Emre Purut ${ }^{2}$, Burak Giray ${ }^{3}$, Gülfidan Bitirgen ${ }^{4}$, Ali Acar ${ }^{5}$

${ }^{2}$ Kadın Hastalıkları ve Doğum Kliniği, Sağlık Bilimleri Üniversitesi, Van Bölge Eğitim ve Araştırma Hastanesi, Van, Türkiye.

${ }^{3}$ Kadın Hastalıkları ve Doğum Kliniği, Sancaktepe Şehit Prof. Dr. İlhan Varank Eğitim ve Araştırma Hastanesi, İstanbul, Türkiye.

${ }^{4}$ Göz Hastalıkları Kliniği, Necmettin Erbakan Üniversitesi, Meram Tip Fakültesi Hastanesi, Konya, Türkiye.

${ }^{5}$ Kadın Hastalıkları ve Doğum Kliniği, Necmettin Erbakan Üniversitesi, Meram Tip Fakültesi Hastanesi, Konya, Türkiye.

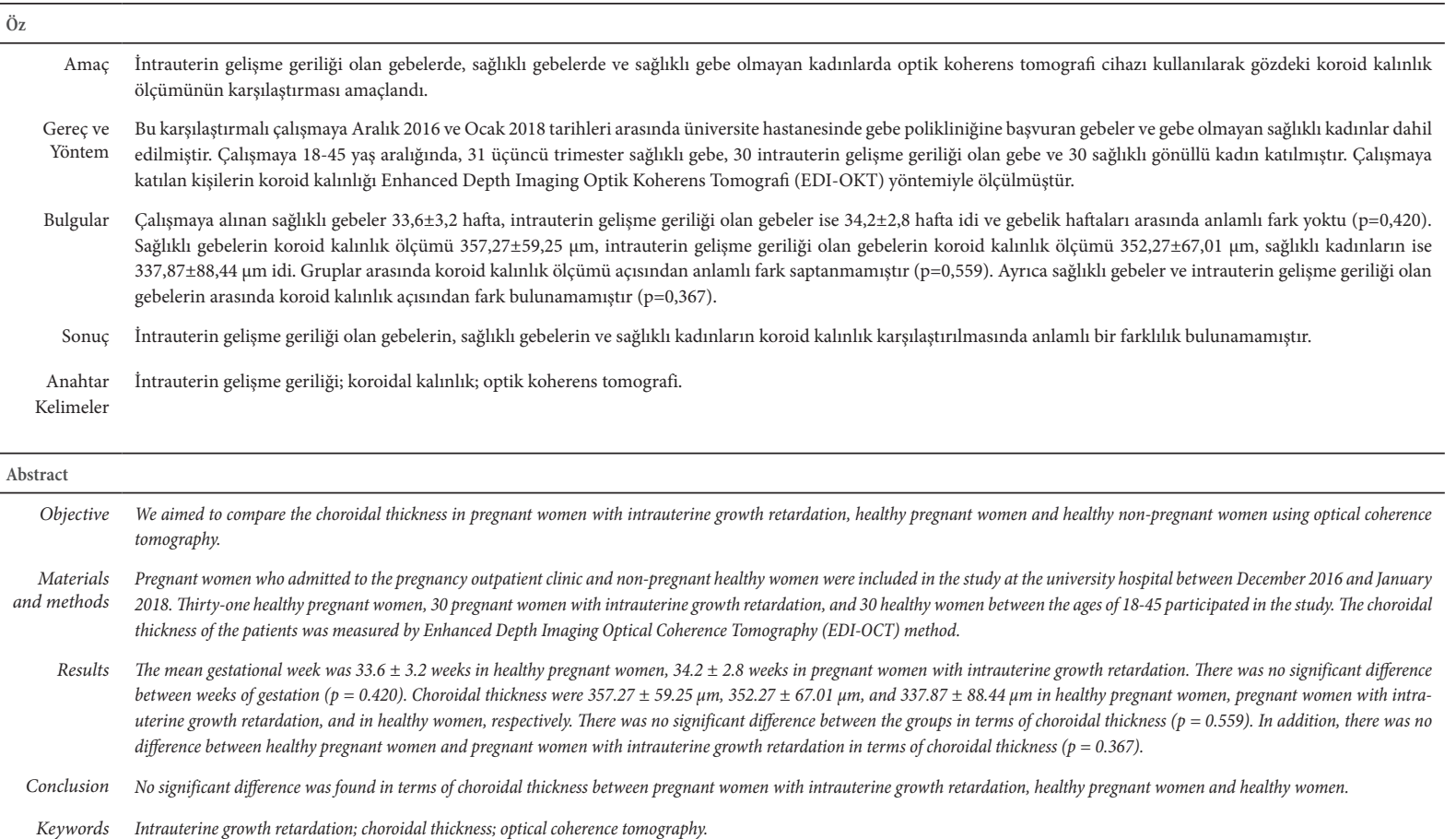




\section{GIIRIș}

Gebelikte vasküler, immünolojik, hormonal ve metabolik değişimler meydana gelir. Bu değişim gösteren sistemlerden bir tanesi de gözdür. Gebelik gözde patolojik değişimler de meydana getirebilir veya önceden var olan göz patolojileri ağırlaşabilir. Daha önceden yapılan çalışmalarda gözde gebelik sırasında birçok değişiklik gözlenmiştir. ${ }^{1-3}$ Gebelikte meydana gelen değişimler kornea duyarlılığında azalış, merkezi korneal kalınlık ve eğriliğinde artış, göz içi basınç artışı ve göz kan akımı artışıdır. Gebelikte koryoretinopati riski artmaktadır ve bunun nedeninin gebeliğe bağlı artmış damar geçirgenliği olduğu düşünülmektedir. ${ }^{4}$ Görüntüleme tekniklerindeki gelişmelere karşın, koroidin halen yeterli olarak görüntülenmesi mümkün olmamaktadır. Optik koherens tomografi (OKT) yakın geçmişte oftalmoloji alanında kullanıma giren, girişimsel olmayan ve temassı ölçüm yapabilen bir görüntüleme yöntemidir. ${ }^{5}$ OKT ışık dalgaları kullanarak retinanın yüksek çözünürlüklü ve kesitsel görüntülemesini sağlar. Yeni geliştirilen bir OKT tekniği olan EDI (enhanced depth imaging) ise, koroid kalınlığı ölçümlerine imkan vermektedir. ${ }^{6}$ Optik koherens tomografi retinal patolojileri daha güzel göstermekle birlikte teknolojideki gelişmelere dayanılarak koroid kalınlık ölçümünde kullanılmaya başlanmıştır. ${ }^{7,8}$ Gebelik koryoretinopati için risk faktörüdür. Gebelik sırasında meydana gelen fizyolojik ve patolojik değişimler koryoretinopati sıklığını artırmaktadır ve EDI-OKT bize bu değişimleri ölçme firsatı vermektedir. Literatürde ayrıca gebe ve gebe olmayan popülasyonda, preeklampsili gebelerde koroid kalınlık EDI-OKT cihazı kullanılarak ölçüm yapılan çalışmalar mevcuttur. ${ }^{9,10}$

Bizim çalışmamızda üçüncü trimester intrauterin gelişme geriliği olan gebelerde, gebe olmayan popülasyonda ve ek hastalığı olmayan üçüncü trimester gebelerde EDI-OKT cihazı kullanılarak koroid kalınlık ölçümünün karşılaştırılması amaçlanmaktadır.

\section{GEREÇ ve YÖNTEMLER}

Bu kesitsel tipte tanımlayıcı araştırmaya Aralık 2016 ve
Ocak 2018 tarihleri arasında üniversite hastanesinde gebe polikliniğine başvuran ve çalışmaya dahil olmayı kabul ederek sözlü/yazılı onam veren gebeler ve gebe olmayan sağlıklı gönüllüler dahil edilmiştir. Çalışmaya 18-45 yaş aralığında, 31 üçüncü trimester sağlıklı gebe, 30 intrauterin gelişme geriliği olan gebe ve 30 sağlıklı gönüllü kadın katılmıştır. Daha önceden tespit edilen bir göz hastalığı veya ek hastalığı olan kadınlar, tansiyon ölçümleri 140/90 mmHg'dan yüksek olan kadınlar, diyabet hastalığı olan kadınlar ve sigara içenler çalışmaya dahil edilmedi. Çalışmaya katılan kişilerin koroid kalınlığı Enhanced Depth Imaging Optik Koherens Tomografi (EDI-OKT) Spectralis ${ }^{\circledR}$ cihazı kullanılarak ölçülmüştür. Her hastanın sağ gözü referans alınmıştır. Subfoveal tabaka ölçümü retina pigment epitelinin hiperrefleksif uç noktasından başlayıp koroidin en uç noktasına fovea çukurunu hizalayıp en uzun vertikal kesit alınarak yapılmıştır. Çalışmaya katılan her kişiden Helsinki bildirisine uygun sözlü ve yazılı onam alınmıştır. Çalışmanın etik kurul onayı Necmettin Erbakan Üniversitesi Meram Tip Fakültesi Etik Kurul Komitesi'nden 18.11.2016 tarihinde alındı (Etik kurul onay numaras1: 2016/723).

$\mathrm{Bu}$ çalışmada istatistiksel analizler Statistical Package for the Social Sciences Version 15.0 (SPSS Inc. Chicago Illinois) programı kullanılarak yapılmıştır. Verilerin değerlendirilmesinde tanımlayıcı istatiksel metotların (ortalama, standart sapma) yanı sıra gruplar arası nicel verilerin karşılaştırılmasında Mann Whitney U testi kullanılmıştır. $\mathrm{P}<0.05$ istatistiksel olarak anlamlı olarak kabul edildi.

\section{BULGULAR}

Çalışmamıza 18-45 yaş aralığında 91 kişi katılmıştır. Katılan kadınların yaş ortalaması $26.96 \pm 5.49$ idi. Grupların yaş ortalamaları arasında anlamlı fark yoktu $(\mathrm{p}=0,118)$ (Tablo 1). Gebelik haftalarına bakıldığında ise sağlıklı gebeler $33,6 \pm 3,2$ hafta, intrauterin gelişme geriliği olan gebeler ise $34,2 \pm 2,8$ hafta idi ve gebelik haftaları arasında anlamlı fark yoktu $(\mathrm{p}=0,420)$ (Tablo 1). Sağlıklı gebelerin koroid kalınlık ölçümü $357,27 \pm 59,25 \mu \mathrm{m}$, intrauterin gelişme geriliği 


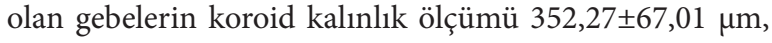

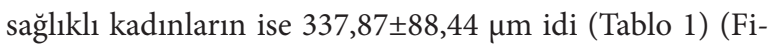
gür 1). Gruplar arasında koroid kalınlık ölçümü açısından anlamlı fark saptanmamıştır $(\mathrm{p}=0,559)$. Ayrıca sağlıklı gebeler ve intrauterin gelişme geriliği olan gebelerin arasında koroid kalınlık açısından fark bulunamamıștır ( $\mathrm{p}=0,367)$.

\begin{tabular}{|c|c|c|c|c|}
\hline & $\begin{array}{l}\text { Sağlıklı } \\
\text { gebeler } \\
(\mathrm{n}=31)\end{array}$ & $\begin{array}{c}\text { İntrauterin } \\
\text { gelişme geriliği } \\
\text { olan gebeler } \\
(\mathrm{n}=30)\end{array}$ & $\begin{array}{c}\text { Sağlıklı } \\
\text { kadınlar } \\
(\mathrm{n}=30)\end{array}$ & $\mathbf{p}$ \\
\hline Yaş & $\begin{array}{c}25,94 \\
\pm 4,62\end{array}$ & $\begin{array}{l}26,33 \\
\pm 4,69\end{array}$ & $\begin{array}{c}28,63 \\
\pm 6,70\end{array}$ & 0,118 \\
\hline $\begin{array}{l}\text { Gebelik } \\
\text { haftası }\end{array}$ & $\begin{array}{r}33,6 \\
\pm 3,2\end{array}$ & $\begin{array}{c}34,2 \\
\pm 2,8\end{array}$ & - & 0,420 \\
\hline $\begin{array}{l}\text { Koroid } \\
\text { kalınlı̆̆ } \\
(\mu \mathrm{m})\end{array}$ & $\begin{array}{r}357,27 \\
\pm 59,25\end{array}$ & $\begin{array}{r}352,27 \\
\pm 67,01\end{array}$ & $\begin{array}{c}337,87 \\
\pm 88,44\end{array}$ & 0,559 \\
\hline
\end{tabular}
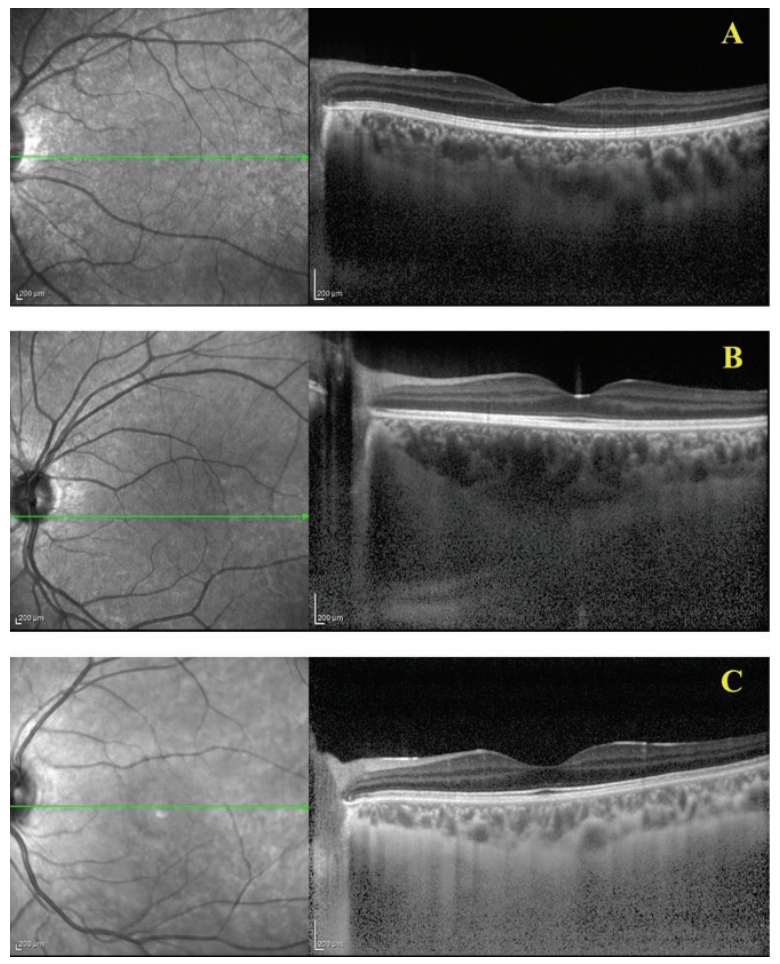

Figür 1: Optik koherens tomografi kullanılarak koroid kalınlık ölçümünü gösteren tablo (A: Sağlıklı kadın, B: Sağlıklı gebe, C: Intrauterin gelişme geriliği olan gebe).

\section{TARTIŞMA}

OKT teknolojisindeki gelişmeler koroid kalınlık ölçümünün değerlendirilmesini kolaylaştırmıştır. Çalışmamızda koroid kalınlık değerlendirilmesi EDI-OKT cihazı kullanılarak yapılmıştır. Gözdeki koroid kalınlığı birtakım faktörlerden etkilenmektedir. Örneğin yaşın artmasıyla beraber koroid kalınlığının azaldığı literatürdeki çalışmalarda gösterilmiştir. ${ }^{8,11,12}$ Ayrıca birtakım çalışmalar da göstermiştir ki gözdeki kırılma kusurları da koroid kalınlığını etkilemektedir. Özellikle miyop hasta grubunda kırılma derecesi ve aksiyal uzunluk azalması koroid kalınlığını azalttığı gösterilmiştir. ${ }^{13,14}$ Bizim çalışmamızda hiçbir hastada gözde kırılma kusuru yoktu. Ayrıca uveal efüzyon sendromu, santral seröz retinopati, Vogt-Koyanagi-Harada hastalığı, polipoidal koroid damar hastalığı ve diabetes mellitus gibi hastalıklarda da koroid tabaka etkilenmektedir. ${ }^{15-17}$

Gebelik özel bir dönemdir. Gebelikte hormonal, hemodinamik, kardiyovasküler, metabolik ve immünolojik değişimler meydana gelir. Gebelikte birinci trimesterden itibaren periferik damar direncinde azalma saptanır. Üçüncü trimesterde periferik damar rezistansı en azdır ve üçüncü trimestere kadar kan volümü de artmaktadır. Buna rağmen, retinal pigment epiteline oksijen ve besin sağlayan ve vücutta en yüksek kan akımlarından birine sahip olan koroidal tabakanın kalınlığının bir çalışmada gebeliğin 3237 haftalarında 6-8 haftalığa göre azaldığı saptanmıştır. ${ }^{18}$ Koroidal kalınlıktaki azalış kanın vital organlara yönelmesinden kaynaklanabilir. ${ }^{19}$ Ayrıca preklampsi ve eklamside posterior segmentte damarsal değişimler meydana gelmektedir.1 Preeklampsi, gebelerde retinal fonksiyon bozuklukları ve koroidal dolaşım bozukluklarına neden olabilir. ${ }^{910}$ Sonuç olarak koroidal iskemi ve damarsal geçirgenlik artışı ve retina altındaki boşlukta ciddi sıvı birikimi olur. Gebelikte meydana gelen bu hemodinamik değişimler koroidal kalınlığın değişime uğrayabileceği fikrini ortaya çıkarmıştır. Bu nedenle bizim çalışmamızda da intrauterin gelişme geriliği olan gebelerde ve sağlıklı gebelikte koroid kalınlık ölçümü farkı araştırılmış, intrauterin gelişme geriliğinde damar direncinde artış olduğu için koroidal 
kalınlıkta değişkenlik saptanabileceği düşünülmüştür. Ancak çalışmamızda intrauterin gelişme geriliği olan gebelerde, normal gebelerde ve normal sağlıklı popülasyonda koroidal kalınlık açısından anlamlı fark bulunamamıştır. Takahashi ve arkadaşlarının yaptığı bir çalışmada ise gebe olan kadınlar ile gebe olmayan kadınlar arasında subfoveal ve parafoveal koroidal tabakanın kalınlığı arasında anlamlı bir fark bulunmamıştır. ${ }^{20}$ Ancak başka bir çalışmada subfoveoal koroidal kalınlık gebe olanlarda gebe olmayan kontrol grubundan anlamlı derecede ince bulunmuştur. ${ }^{21}$ Kara ve arkadaşlarının yaptığ 1 diğer bir çalışmada ise gebe ve gebe olmayan grup arasında subfoveal koroid kalınlık ölçümlerini karşılaştırdılar ve diğer çalışmaların aksine gebe kadınlarda subfoveal koroidal kalınlığın daha fazla olduğunu rapor ettiler. ${ }^{22}$ Taradaj ve arkadaşlarının yaptığı bir çalışmada ise üçüncü trimesterde koroidal kalınlığı doğum sonrası altıncı haftaya göre daha ince bulmuşlardır. ${ }^{23}$ Mevcut çalışmamızın bazı kısıtlılıkları bulunmaktadır. Nispeten küçük örneklem büyüklüğü çalışmamızın kısıtlılığı olarak gösterilebilir. Az hasta sayısından dolayı arada fark çıkmamış olabileceği de düşünülmelidir.

Sonuç olarak, üçüncü trimester intrauterin gelişme geriliği olan gebelerin, üçüncü trimester sağlıklı gebelerin ve sağlıklı kadınların koroid kalınlık karşılaştırılmasında anlamlı bir farklılık bulunamamıştır.

\section{Çıkar Çatışması}

Yazarların makalede geçen ürün, firma ya da cerrahi/tıbbi tedavi yöntemleriyle hiçbir çıkar çatışması yoktur.

\section{Finansal Destek}

Herhangi bir finansal destek alınmamıştır.

\section{Hasta Onamı}

Katılımcılardan bilgilendirilmiş onam almıştır.

\section{Etik kurul onayı}

Çalışmanın etik kurul onayı Necmettin Erbakan Üniversitesi Meram Tip Fakültesi Etik Kurul Komitesi'nden 18.11.2016 tarihinde alındı (Etik kurul onay numaras1: 2016/723). 
Sakarya Tip Dergisi 2021;11(2):395-399

CAN ve Ark., İntrauterin Gelișme Geriliği Olan Gebelerde Koroid Kalınlığı

\section{Kaynaklar}

1. Errera MH, Kohly RP, da Cruz L. Pregnancy-associated retinal diseases and their management. Surv Ophthalmol 2013;58(2):127-42.

2. Rhee P, Dev S, Mieler WF. The development of choroidal neovascularization in pregnancy. Retina 1999;19(6):520-4

3. Polizzi S, Mahajan VB. Intravitreal anti-VEGF injections in pregnancy: case series and review of literature. J Ocul Pharmacol Ther 2015;31(10):605-10.

4. Pole C, Gaw Stephanie SL, Tsui Irena I. Utility of optical coherence tomography angiography in pregnancy-associated central serous chorioretinopathy. Am J Ophthalmol Case Rep 2020;20:100979.

5. Yeoh J, Rahman W, Chen F, Hooper C, Patel P, Tufail A, et al. Choroidal imaging in inherited retinal disease using the technique of enhanced depth imaging optical coherence tomography. Graefes Arch Clin Exp Ophthalmol 2010;248(12):1719-28.

6. Spaide RF, Koizumi H, Pozonni MC. Enhanced depth imaging spectral-domain optical coherence tomography. Am J Ophthalmol 2008;146(4):496-500.

7. Margolis R, Spaide RF. A pilot study of enhanced depth imaging optical coherence tomography of the choroid in normal eyes. Am J Ophthalmol 2009;147(5):811-5.

8. Regatieri CV, Branchini L, Fujimoto JG, Duker JS. Choroidal imaging using spectral-domain optical coherence tomography. Retina 2012;32(5):865-76.

9. Ferreira BFA, Kreuz AC, Diniz PM, Rocha JVSS, Pimentel SLG. Spontaneous outer retinal layer recovery in a case of hypertensive choroidopathy secondary to pre-eclampsia: a multimodal evaluation. Arq Bras Oftalmol 2019;82(6):522-7.

10. Jiang MS, Xu XL, Yang T, Li F, Zhang XD. Comparison of Choroidal Thickness in Preeclamptic, Healthy Pregnant, and Nonpregnant Women: A Systematic Review and Meta-Analysis. Ophthalmic Res 2019;62(1):1-10.

11. Ikuno Y, Kawaguchi K, Nouchi T, Yasuno Y. Choroidal thickness in healthy Japanese subjects. Invest Ophthalmol Vis Sci 2010;51:2173-6.

12. Agawa T, Miura M, Ikuno Y, Makita S, Fabritius T, Iwasaki T, et al. Choroidal thickness measurement in healthy Japanese subjects by three-dimensional high-penetration optical coherence tomography. Graefes Arch Clin Exp Ophthalmol 2011;249:1485-92.
13. Fujiwara T, Imamura Y, Margolis R, Slakter JS, Spaide RF. Enhanced depth imaging optical coherence tomography of the choroid in highly myopic eyes. Am J Ophthalmol 2009; 148:445-50.

14. Nishida Y, Fujiwara T, Imamura Y, Lima LH, Kurosaka D, Spaide RF. Choroidal thickness and visual acuity in highly myopic eyes. Retina 2012;32:1229-36.

15. Maruko I, Iida T, Sugano Y, Ojima A, Sekiryu T. Subfoveal choroidal thickness in fellow eyes of patients with central serous chorioretinopathy. Retina 2011;31(8):1603-8.

16. Harada T, Machida S, Fujiwara T, Nishida Y, Kurosaka D. Choroidal findings in idiopathic uveal effusion syndrome. Clin Ophthalmol 2011;5:1599-601.

17. Baltmr A, Lightman S, Tomkins-Netzer O. Vogt-Koyanagi-Harada syndrome-current perspectives. Clin Ophthalmol 2016;10:2345-61.

18. Temel E, Kocamıș Ö, Așıkgarip N, Örnek K, Arıöz O. Evaluation of choroidal thickness and choroidal vascularity index during pregnancy. Can J Ophthalmol 2021:S00084182(20)30836-X.

19. Whittaker PG, Macphail S, Lind T. Serial hematologic changes and pregnancy outcome. Obstet Gynecol 1996;88:33-9.

20. Takahashi J, Kado M, Mizumoto K, Igarashi S, Kojo T. Choroidal thickness in pregnant women measured by enhanced depth imaging optical coherence tomography. Jpn J Ophthalmol 2013;57(5):435-9.

21. Su L, Taweebanjongsin W, Gaw SL, Rabina G, Sadda SR, Tsui I. Evaluation of the Choroid in Women with Uncomplicated Pregnancy. Transl Vis Sci Technol 2020;9(9):24.

22. Kara N, Sayin N, Pirhan D, Vural AD, Araz-Ersan HB, Tekirdag AI, et al. Evaluation of subfoveal choroidal thickness in pregnant women using enhanced depth imaging optical coherence tomography. Curr Eye Res 2014;39(6):642-7.

23. Taradaj K, Ginda T, Maciejewicz P, Suchonska B, Wielgos M, Kecik D, et al. Does pregnancy influence eye parameters? Assessment of choroidal thickness using EDI-OCT before and after labour depending on the way of delivery method. Ginekol Pol 2020;91(11):668-73. 